Gut $1971,12,51-54$

\title{
Double-blind clinical trial of the analgesic effects of phenazocine hydrobromide (Narphen) compared with morphine sulphate in patients with acute abdominal pain
}

\author{
DAVID HOPTON \\ From the Cardiff Royal Infirmary, Cardiff
}

SUMMARY No significant difference could be detected either by clinical impression or statistical analysis in the relief of pain afforded by $2.5 \mathrm{mg}$ phenazocine hydrobromide (Narphen) and $10 \mathrm{mg}$ morphine sulphate when given by intramuscular injection to patients with acute abdominal pain. Phenazocine does not cause spasm of the sphincter of Oddi and so is recommended for treating biliary or pancreatic pain.

The spasmodic side effects of morphine have been recognized for many years and it is standard teaching that this drug should not be used to treat patients with pancreatitis because it causes a rise in the biliary and pancreatic pressure (Bailey and Love, 1965). Phenazocine hydrobromide (Narphen) is a strong analgesic which does not cause a rise in the common bile duct pressure (Hopton and Torrance, 1967), and I have confirmed this finding by additional observations.

Previously published studies on the analgesic properties of phenazocine were carried out either on patients after operation or they were not controlled trials (Sadove, Schriffin, and Heller, 1959; di Pillo, Younger, Scarpa, and Edson, 1960; Fisch, 1960; Prevozink and Eckenhoff, 1960; Swerdlow, Starmer, and Daw, 1964). No studies have been reported on the effectiveness of this drug in treating acute abdominal pain. In consequence, this trial was conducted with the object of assessing the value of phenazocine in patients admitted to a surgical unit as emergencies because of acute abdominal pain.

\section{Materials and Method}

Because of the difficulty of establishing the cause of pain at the time of admission to hospital and in order to collect sufficient numbers of patients in a reasonable length of time, any patient with severe abdominal pain who needed a strong analgesic was admitted to the study. The patients were Received for publication 29 September 1970. classified retrospectively by the diagnosis which was eventually made. If, however, the initial assessment of the patient strongly suggested a diagnosis of acute pancreatitis, then the patient was not included in the trial because the drug administered might have been morphine. It was considered that morphine should not be used for such patients and they were given phenazocine or pethidine.

The two drugs were prepared by the manufacturers of phenazocine in $2 \mathrm{ml}$ ampoules for intramuscular injection which were labelled ' $A$ ' and ' $B$ '. ' $A$ ' contained $2.5 \mathrm{mg}$ phenazocine hydrobromide and ' $B$ ' contained $10 \mathrm{mg}$ morphine sulphate. In the hospital, only the chief pharmacist knew which letter corresponded to each drug and they were described on the patient's chart as 'treatment $\mathbf{A}^{\mathbf{y}}$ or 'treatment B' according to a predetermined random order. In addition to the analgesic drugs, antibiotics and intravenous therapy were also given if these were considered necessary.

Patients of both sexes were admitted to the study and age was recorded in 10-year blocks. Minors (under 16) were excluded.

\section{PAIN CATEGORIES AND SCORING}

The pain was assessed as being very severe, severe, moderate, slight, or none, and each category was given a score between 0 for no pain and 4 for very severe pain (Table I).

At the time of initial assessment, that is, when the injection was given, the severity of the pain was recorded. Subsequently, at one, two, four, and six 


\begin{tabular}{lll}
\hline Pain & Clinical Description & Score \\
\hline Very severe & $\begin{array}{l}\text { Patient moving about in bed and/or crying } \\
\text { out because of severity of pain }\end{array}$ & 4 \\
Severe & $\begin{array}{l}\text { Able to control himself but obviously } \\
\text { distressed }\end{array}$ & 3 \\
Moderate & $\begin{array}{l}\text { Pain of lesser severity but analgesics still } \\
\text { indicated }\end{array}$ & 2 \\
Slight & Patient aware of discomfort & 1 \\
None & & 0 \\
\hline
\end{tabular}

Table I The definition of the pain categories

hours after the injection, the patient's pain category was again recorded. A pain relief score could then be calculated for each injection by subtracting the score at reassessment times from the initial pain score. Thus if the initial pain was severe a score of 3 was given. If after one hour the pain was moderate a score of 2 was given and the relief score was 1 . If subsequently within six hours of the injection the pain disappeared completely, a score of 0 was allotted and the relief score was 3 .

Assessment of the severity of the pain was made by asking the patient what his pain was like. If the patient was sleeping the pain was recorded as slight. Some observations were made by the senior nurse on duty and in this case they were subsequently checked by the author by questioning the patient on his recollections.

\section{Results}

Fifty patients were admitted to the trial between August 1968 and August 1969.

Several patients were considered suitable for the trial when seen in the receiving room but when settled in bed pain subsided to such an extent that no analgesic was administered. It is of interest that some of these patients subsequently had emergency operations at which were found pathological changes justifying the severity of the original pain, bearing testimony to the effectiveness of admission to hospital and bed rest in relieving abdominal pain.

When the results sheets were analysed one record contained insufficient data for inclusion, and so 27 patients who had treatment $A$ and 22 patients who had treatment $B$ were available for comparison. Thirty patients had a second injection and eight patients had three or more injections. Insufficient data were available for numerical comparison of the effectiveness of the response other than to the first and second injections. Each second injection which was assessed was given six hours or more after the first injection.
The age distribution of the patients is given in Table II; Table III shows the retrospective diagnosis of the patients and which drug was administered. It is apparent that the ages of the patients who were given each drug were similarly distributed. In particular, the biliary patients were predominantly older. The patients in the 21-30 age group were mostly suffering from renal pain or appendicitis.

\begin{tabular}{lllllllll}
\hline \multicolumn{7}{l}{ Age group $(y r)$} \\
\cline { 2 - 7 } & 20 & $21-30$ & $31-40$ & $41-50$ & $51-60$ & $61-70$ & $70+$ \\
\hline $\begin{array}{l}\text { Phenazocine } \\
\text { All patients }\end{array}$ & 1 & 5 & 3 & 4 & 6 & 3 & 5 \\
Biliary pain only & & 1 & 1 & 2 & 3 & 3 & 3 \\
$\begin{array}{l}\text { Morphine } \\
\text { All patients }\end{array}$ & 1 & 5 & 1 & 2 & 4 & 7 & 2 \\
Biliary pain only & & 1 & & 1 & 2 & 1 & 2 \\
\hline
\end{tabular}

Table II Age distribution of the patients in the two treatment groups

\begin{tabular}{|c|c|c|c|c|}
\hline \multirow[t]{2}{*}{ Diagnosis } & \multicolumn{2}{|c|}{ Phenazocine } & \multicolumn{2}{|c|}{ Morphine } \\
\hline & Female & Male & Female & Male \\
\hline Biliary pain & 12 & 1 & 7 & 0 \\
\hline Acute pancreatitis & 1 & 1 & & \\
\hline Appendicitis & & 1 & 3 & \\
\hline Epididimoorchitis & & 2 & & \\
\hline Intestinal obstruction & 1 & & 1 & 1 \\
\hline Carcinoma colon and obstruction & 1 & & 1 & \\
\hline Diverticulitis & & 1 & 3 & \\
\hline Renal colic & 2 & 4 & & 4 \\
\hline Carcinoma pancreas & & & & 1 \\
\hline Ruptured uterus (postpartum) & & & 1 & \\
\hline Total & 17 & 10 & 16 & 6 \\
\hline
\end{tabular}

Table III Sex distribution of the patients and the retrospective diagnosis

No difference between the effectiveness of treatment A and treatment B was detected by the medical and nursing staff during the course of the trial.

The mean initial pain score for all first injections in the 27 patients given phenazocine (treatment $A$ ) was $3 \cdot 1 \pm 0 \cdot 7$. Eight patients had very severe pain, 13 patients had severe pain, and six patients had moderate pain. The mean initial pain score for all the first injections in the 22 patients given morphine (treatment B) was $3.0 \pm 0.5$. Six patients had very severe pain, 13 patients had severe pain, and three had moderate pain.

The mean scores for pain relief at one, two, four, and six hours for both the first and the second injections were calculated for phenazocine and morphine. This was calculated for all the patients who were given each drug and and also separately for the patients who had biliary pain. Morphine appeared consistently to afford marginally more pain relief 
than phenazocine, but at no time interval after the injections was the difference in pain relief afforded by phenazocine and morphine significant at the $5 \%$ level (Tables IV and V).

\begin{tabular}{|c|c|c|c|c|c|}
\hline \multirow[t]{2}{*}{ Patient } & \multirow{2}{*}{$\begin{array}{l}\text { Initial } \\
\text { Pain } \\
\text { Score }\end{array}$} & \multicolumn{4}{|c|}{ Mean Pain Relief Score } \\
\hline & & $\begin{array}{l}\text { First } \\
\text { Hour }\end{array}$ & $\begin{array}{l}\text { Second } \\
\text { Hour }\end{array}$ & $\begin{array}{l}\text { Fourth } \\
\text { Hour }\end{array}$ & $\begin{array}{l}\text { Sixth } \\
\text { Hour }\end{array}$ \\
\hline
\end{tabular}

Phenazocine

All patients (27) $\quad 3.1 \pm 0.7 \quad 1.5 \pm 1.01 .6 \pm 1.01 .6 \pm 0.91 .6 \pm 1.0$

Biliary pain only (13) $2.9 \pm 0.8 \quad 1.5 \pm 0.7 \quad 1.7 \pm 0.9 \quad 1.7 \pm 1.0 \quad 2.0 \pm 0.9$

Morphine

All patients (22) $\quad 3.0 \pm 0.5 \quad 1 \cdot 9 \pm 0.8 \quad 2 \cdot 1 \pm 0 \cdot 7 \quad 2 \cdot 2 \pm 0.9 \quad 2 \cdot 0 \pm 0.9$

Biliary pain only (7) $\quad 2 \cdot 6 \pm 0.5 \quad 1.7 \pm 0.8 \quad 2 \cdot 0 \pm 0.02 \cdot 0 \pm 0.7 \quad 1 \cdot 6 \pm 0.9$

Table IV Mean pain relief after the first injection ${ }^{1}$

${ }^{1}$ Differences between phenazocine and morphine were not significant at the $5 \%$ level.

\begin{tabular}{llllll}
\hline Patient & $\begin{array}{l}\text { Initial } \\
\text { Pain }\end{array}$ & \multicolumn{3}{l}{ Mean Pain Relief Score } \\
\cline { 3 - 5 } & Score & First & Second & Fourth & Sixth \\
& & Hour & Hour & Hour & Hour \\
\hline
\end{tabular}

Phenazocine

All patients (20) $\quad 2.8 \pm 0.81 .6 \pm 0.71 .9 \pm 0.81 .8 \pm 0.81 \cdot 7 \pm 1 \cdot 1$

$\begin{array}{llll}\text { Biliary pain only (10) } 2.7 \pm 0.8 & 1.7 \pm 0.7 & 1.8 \pm 0.5 & 1.9 \pm 0.7\end{array}$

Morphine

All patients (10) $\quad 2.5 \pm 0.5 \quad 1.6 \pm 0.5 \quad 1.9 \pm 0.3 \quad 1.8 \pm 0.7 \quad 1.4 \pm 0.8$

Biliary pain only (3) $2.3 \pm 0.6 \quad 2.0 \pm 0.02 .0 \pm 0.02 .0 \pm 0.0$

Table V Mean pain relief after the second injection ${ }^{1}$

${ }^{1}$ Differences between phenazocine and morphine were not significant at the $5 \%$ level.

Pain levels at the time of the second injection were consistently lower than at the first injection. The pain relief afforded by the drugs was similar to that recorded after the first injection and again morphine was marginally more effective, but the difference was not significant at the $5 \%$ level.

Phenazocine was given to 13 patients and morphine was given to seven patients who had biliary pain. The numerical assessment of mean pain relief at each interval after both the first and the second injection for this smaller group, as for all the patients, suggested that morphine afforded slightly more relief than phenazocine but the difference was not statistically significant. There was no difference in the response to either drug if the pain was colicky or constant.

No distressing side effect such as nausea or vomiting was reported by the patients in response to either phenazocine or morphine.

\section{Discussion}

The method of scoring pain relief is admittedly open to question because it certainly cannot be claimed that pain can be accurately categorized by a linear scale. Similar scoring has, however, been adopted in previous trials (Keele, 1948; Lasagna, 1960), and the weaknesses in the method were applicable to both groups of patients who were being compared. Also, the degree of pain at any particular time was a subjective judgment based on the patient's comments and thus affected by the unmeasurable influence of emotion and personality. Sometimes the patient was sleeping at the time of assessment, and then the pain was recorded as slight. If the patient had been awakened and asked his opinion he might not have agreed with this assessment. Lasagna (1960) woke up a group of patients to ask them about their pain and found that $76 \%$ reported slight or no pain, $22 \%$ reported moderate pain, and $2 \%$ reported severe pain. On this basis, our assessment of the pain in the sleeping patients was correct in three out of four instances.

The equianalgesic doses of phenazocine and morphine were based on the study made by House et al (1964), which showed that for peak analgesic effect $2 \cdot 3 \mathrm{mg}$ of phenazocine was equivalent to $10 \mathrm{mg}$ of morphine and that for 'overall effect', $3.2 \mathrm{mg}$ of phenazocine was equivalent to $10 \mathrm{mg}$ of morphine. These studies were made on patients suffering from cancer and so may not be strictly comparable to the effects on acute abdominal pain. However, the commercially available phenazocine ampoules contain $2 \mathrm{mg}$ only, and so to conform with the dose range (Houde 1964) the special ampoules for this trial were made up to contain $2.5 \mathrm{mg}$ of phenazocine and $10 \mathrm{mg}$ of morphine. The consistently slightly greater effect of the morphine probably means that analgesic equality of dosage was not achieved.

The relief scores suggest that neither drug was giving complete pain relief in most instances but probably this is not attainable in the presence of acute illness without rendering the patient comatose. It is, however, commonly accepted that most adults require $15 \mathrm{mg}$ of morphine if pain is severe enough to merit strong analgesics at all. This higher dosage scale was discussed when the trial was being designed, but the ampoules were made up to a lower dosage because it was considered that if necessary a second smaller dose could be given if the initial injection was insufficient. As phenazocine is marketed in $2 \mathrm{mg}$ ampoules the most suitable dose to use would probably be two ampoules in an average adult.

The second injection was generally more effective than the first injection. This was probably because 
some of the effect of the first injection lingered on for more than six hours and into the period covered by the second injection (Lasagna, 1960), and also partly due to the natural response of a decrease in pain and anxiety in any patient who is put to bed in hospital and given other supportive treatment.

It might be suggested that, as both morphine and phenazocine give equal pain relief, there is no need to change the accepted management of biliary pain. This line of reasoning, however, assumes that the treatment of the pain is paramount in the management of such patients. The pain is but one aspect of the pathological process occurring in the patient, and morphine, in theory at least, might increase the risk of extending the local damage either in the biliary tract or in the pancreas by increasing the biliary pressure.

In a previous communication the lack of spasmodic action of phenazocine was demonstrated (Hopton and Torrance,1967). In more recent studies, which have not been published, biliary pressures were measured through a T-tube draining the common bile duct in 20 patients, Morphine caused a mean biliary pressure rise of $7 \cdot 4 \pm 3 \cdot 1 \mathrm{~cm}$. Phenazocine in the same patients caused a mean pressure rise of only $1.4 \pm 1.5 \mathrm{~cm}$ and in some of these patients a fall in pressure was recorded. Morphine caused a rise in pressure in excess of $10 \mathrm{~cm}$ on several occasions whereas a maximum rise of only $4 \mathrm{~cm}$ was recorded after phenazocine.

Phenazocine has thus been shown to be almost completely free of the possibly hazardous spasmodic side effect of morphine and to a lesser extent of pethidine and it also gives comparable relief of pain. It would, therefore, appear that phenazocine is a more suitable analgesic drug to treat patients with pain arising from disease in the biliary tract or the pancreas.

The author wishes to thank the pharmaceutical, medical, and nursing staff at the Cardiff Royal Infirmary for their help in conducting this study. Smith and Nephew Pharmaceuticals Ltd provided the special ampoules of phenazocine and morphine.

\section{References}

Bailey, H., and Love, R. J. M. (1965). In a short Practice of Surgery, 13th ed., edited by A. J. H. Rains and W. M. Capper. p. 886. Lewis, London.

Fisch, S. (1960). Clinical studies with phenazocine: the effect on pain. Bull. Drug. Addict. Narcot. Addend., 3, 73-77.

Hopton, D. S., and Torrance, H. B. (1967). Action of the various analgesic drugs on the human common bile duct. Gut, 8, 296-300.

Houde, R. W. (1964). The relative analgesic and respiratory effects of phenazocine and morphine. J. Pharmacol. Expt. Ther., 144, 337-345.

Keele, K. D. (1948). The pain chart. Lancet, 2, 6-8.

Lasagna, L. (1960). The clinical measurement of pain. Ann. N.Y. Acad. Sci., 86, 28-37.

Pillo, F. di, Younger, M. D., Scarpa, W. J., and Edson, J. N. (1960). Phenazocine: its clinical use as an analgesic. Bull. Drug Addict. Narcot. Addend., 3, 69-72.

Prevoznik, S. J., and Eckenhoff, J. E. (1960). The use of phenazocine (prinadol) in surgical patients. Surg. Gynec. Obstet., 110, 669-672.

Sadove, M. S., Schriffin, M. J., and Heller, R., Jr. (1959). A clinical comparison of two new narcotic analgesics. Curr. ther. Res., 1, 109-114.

Swerdlow, M., Starmer, G., and Daw, R. H. (1964). A comparison of morphine and phenazocine in postoperative pain. Brit. $J$. Anaesth., 36, 782-786. 